\title{
A Mechanism for Forming Large Fluorescent Organo-Silica Particles: Potential Supports for Combinatorial Synthesis
}

\author{
Angus P. R. Johnston, ${ }^{a}$ Bronwyn J. Battersby, ${ }^{a}$ Gwen A. Lawrie, ${ }^{a}$ Lynette K. Lambert ${ }^{b}$ \\ and Matt $\operatorname{Trau}^{\mathrm{a} *}$ \\ ${ }^{a}$ Centre for Nanotechnology and Biomaterials, ${ }^{b}$ Centre for Magnetic Resonance, \\ The University of Queensland, Queensland 4072, Australia.
}

\section{Supplementary Information}

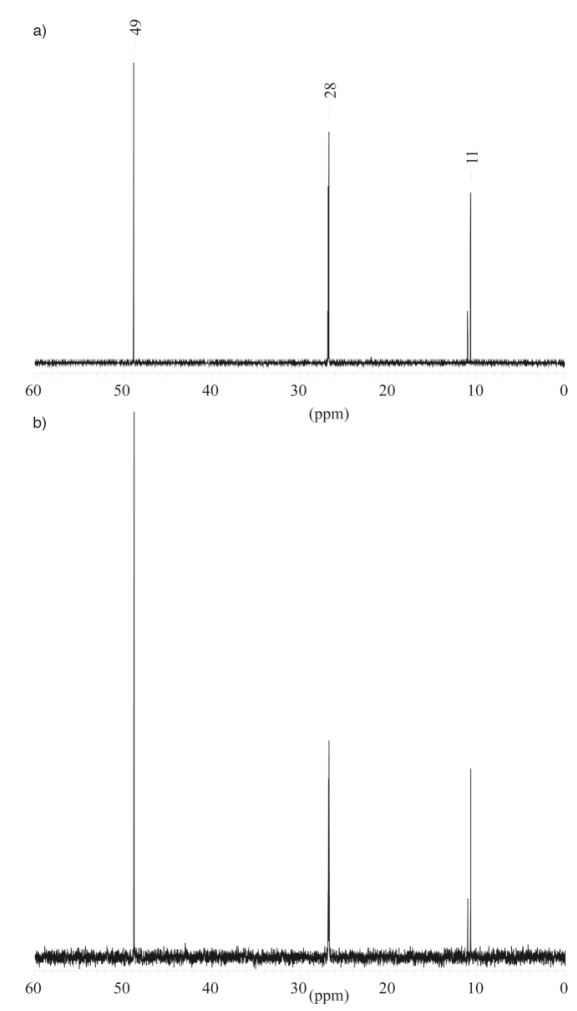

Figure S1: ${ }^{13}$ C NMR. a) After 2 hours, three regions of peaks were present in the spectrum; the peaks in the regions of $11-12 \mathrm{ppm}$ and $26-27 \mathrm{ppm}$ due to the carbons in the propyl chain and a third peak at $49 \mathrm{ppm}$; b) The peak at 49ppm was confirmed to be due to methanol by the addition of $10 \mu \mathrm{l}$ of methanol to the NMR tube, re-running the spectrum and observing an increase in intensity of the peak at 49ppm. 